\title{
EL DIABLO DEL CARNAVAL DE RIOSUCIO: \\ ÍCONO Y MATACHÎN DE UN PUEBLO CARNAVALERO
}

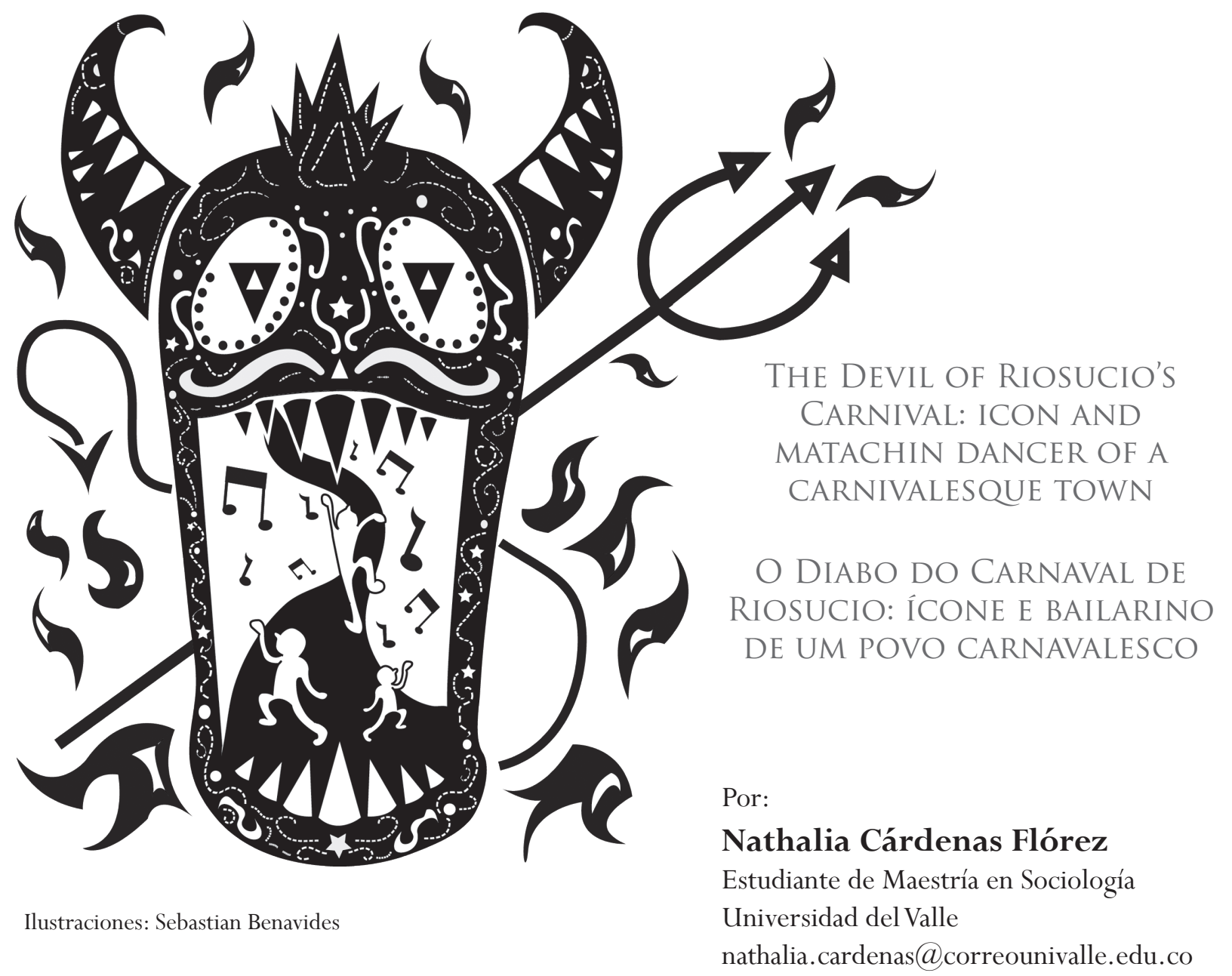

Resumen: Este artículo es uno de los resultados del proyecto de investigación: Recreación/Fiesta y Educación: Un estudio del Carnaval de Riosucio como experiencia recreativa y organizativa ${ }^{1}$. Su propósito se centra en entender el papel pedagógico y el sentido de la construcción social del diablo como personaje icónico en el Carnaval de Riosucio, Caldas. Para ello, se hace una revisión histórica del papel del diablo en las festividades latinoamericanas. Se analizan las formas organizativas y festivas que devienen de la actuación del diablo riosuceño.Y concluye con la descripción de las efigies de los diablos participantes en el Carnaval de Riosucio $2013^{2}$.

Palabras Claves: Recreación, Educación, Carnaval de Riosucio, Diablo, Mito. 
Abstract: This article is one of the results from the research project: Recreation/ Party and Education: A study of Riosucio's Carnival as a recreational and organizational experience. Its purpose is focused on understanding the pedagogical role and meaning of the social construction of the devil as an iconic character in Riosucio's Carnival, Caldas. For that, it's made a historical review of the role of the devil in latin americans festivities. Are analyzed the organizational and festive forms that arise from the performance of the riosuceño devil. And it's concluded by describing the participant devils' effigy (image) in the Carnival of Riosucio 2013.

Keywords: Recreation, Education, Riosucio's Carnival, Devil, Myth.

Resumo: Este artigo é um dos resultados do projeto de pesquisa Recreação / Festa e Educação: um estudo do Carnaval de Riosucio como experiência recreativa e organizativa. O seu propósito está enfocado em compreender o papel pedagógico e o sentido da construção social do diabo como personagem icónico no Carnaval de Riosucio, Caldas. Para isso, se faz uma revisão histórica do papel do diablo nas festividades de América Latina, e se examinam as formas organizativas e festivas que devêm da atuação do diabo de Riosucio. O texto conclui com a descrição das efígies dos diabos participantes no Carnaval de Riosucio 2013.

Palavras-chave: Recreação, Edução, Carnaval de Riosucio, Diabo, Mito.

\section{El diablo latinoamericano}

La figura del diablo ha protagonizado a lo largo de la historia humana todo tipo de discusiones y representaciones fundamentadas desde lo filosófico, lo teológico y lo religioso. Esta ha sido una construcción sociocultural que ha variado según cada sociedad y su cosmogonía. Se ha concebido al diablo como un hecho concreto, como una serie de acontecimientos, un comportamiento, un personaje o un hábito. Sin embargo, todas estas miradas coinciden en algo: el diablo es una representación simbólica del mal, la cual es la explicación a fenómenos externos y necesidades internas que encuentran justificación en un agente supremo; tal cual como Dios. Bajo esa lógica, han sido muchas las funciones atribuidas al diablo y manifestadas a través de un sin fin de fenómenos enmarcados dentro de actos de brujería, rituales, pecados, desenfreno y fiestas paganas (Arboleda, 2011; Bueno, 2012).

La estrecha relación entre el diablo y la fiesta se ha reflejado en los excesos, permisos y libertad que la misma posibilita. El diablo festivo también ha sido adoptado y moldeado por diferentes culturas y su uso puede ir desde la transgresión del orden de lo estético y lo político, hasta la unión y la reivindicación en movimientos sociales. Esta visión del diablo responde también a las concepciones culturales que se transforman con las épocas, que modifican discursos, abren fronteras y estructuran nuevos paradigmas. Por ejemplo, antes de la edad media y la propagación del cristianismo, el diablo era considerado entre griegos y romanos como una figura que evocaba la celebración, era un dios más entre todos los que existían (Idoyaga \& Torres, 2007). 
Para el caso de Latinoamérica la diferencia no ha sido muy grande. El diablo terminó siendo un gran sincretismo de procesos de entrecruzamiento étnico-político diferentes y violentos. Así, la figura del diablo encarna el simbolismo y la representación de los diversos procesos sociopolíticos y culturales convergentes en Latinoamérica, los cuales encuentran en la fiesta una estrategia para sobrevivir a través del tiempo, conmemorar las derrotas y las muertes, celebrar los triunfos y la resistencia (Rodríguez, 2012; Morales, 1989; Vignolo, 2008).

En ese sentido, la diversidad de fiestas, festivales, ferias y carnavales en Latinoamérica posibilitan dimensionar el valor de lo festivo en este territorio. Se encuentran, por ejemplo, una gran cantidad de fiestas y carnavales que incorporan en su celebración y en diferentes dimensiones la figura del diablo; cada una estructurada desde sus necesidades, procesos socioculturales y experiencias colectivas. Así, hablar del diablo en los carnavales de Colombia no resultará igual que hacerlo en los de otros países. Para comprender entonces dicha diversidad, resulta necesario hacer una revisión rápida de algunas fiestas latinoamericanas que acuden al diablo como símbolo de resistencia cultural, social y política. En ellas, los elementos estéticos que componen la figura del diablo marcan la diferencia y arrojan un "mapa narrativo" de su concepción.

En Colombia, el Carnaval de Riosucio, los Diablos Arlequines de Barranquilla y los Diablos Danzantes de Valledupar y Atánquez, conforman la cuota nacional de fiestas que incorporan en sus festejos la figura del diablo festivo y poderoso. Unas con más protagonismo que otras y con una relación más estrecha con la religión. El Carnaval de Oruro en Bolivia adorna con cachos los trajes de algunas de sus danzas, las cuales convergen en sus movimientos y colores elementos de su historia andina con la imagen del diablo impuesta por la colonización. Los Diablos Danzantes,
Diablos de Chuao, Diablos de Ocumare y los Diablos de Cata, hacen parte de una tradición de danzas en Venezuela que integra rituales, música y desfiles de comparsas bajo el marco de la celebración del Corpus Christi. Trinidad y Tobago cuenta con los Diablos Azules en Paramin, desfile que rememora la época del esclavismo, en donde los negros acudían a pintarse de color azul durante las celebraciones para poder burlarse de sus 'amos'. Los Cachuas de República Dominicana, representan al diablo castigador a través del uso de látigos que aluden a la violencia. Mientras tanto, Argentina con el Carnaval de Tilcara, ofrece nueve días en los que el diablo revive durante cada año y otorga permisos al pueblo para bailar, reír y arrojarse harina y agua. El Juego de los Diablos en Costa Chica, México, llevado a cabo en el Día de los Muertos, consiste en una danza que recorre el pueblo conmemorando las prácticas esclavistas a las que la población afrodescendiente fue sometida; los diablos bailan, hacen chistes e interactúan con los habitantes. Por otra parte, Ecuador cuenta con los Diablos Huma, personajes danzantes que participan en las Fiestas del Sol de las diferentes regiones del país, en las que se agradece a la naturaleza por las cosechas a través de peregrinaciones y festejos. Otros países como Perú, Brasil, Cuba y Uruguay, incorporan de manera similar la figura del diablo, sincretismo entre festejos religiosos, tradiciones andinas o afrodescendientes y prácticas artísticas populares (Torres, 2002; Morales, 1989; Vignolo, http: / / www.diablosfestivos.org/).

Cada una de las celebraciones incorpora diversas formas estéticas que materializan, desde lo simbólico, la relación entre la concepción festiva del diablo y su capacidad para hacer parte de las celebraciones populares desde una representación jocosa y libre de antecedentes de odio, venganza y corrupción. La mayoría de ellas le apuestan a la conservación de prácticas artísticas tradicionales que dan cuenta de una historia negociada, es decir, 
que la concepción del diablo en las diferentes tradiciones populares ha estado, en mayor medida y según Soto (2012), anclada a manifestaciones artísticas como la danza, la música y la literatura -mitos y leyendas.

Con dicho panorama, concebir al diablo como el ícono de un carnaval nos remite a pensar quizá en una especie de fiesta pagana, sin embargo, "su majestad" - como lo denominan en Riosucio, Caldas- aparece con su máxima expresión de magia, picardía y poder en uno de los carnavales que aún conserva grandes rasgos de lo popular, el cual, une cada dos años a locales y turistas en este pueblo de Colombia. Entonces, ¿por qué sigue siendo tan controversial la figura del diablo dentro de un carnaval y qué hace diferente al de Riosucio?

El diablo de este carnaval constituye una figura compleja, particular y festiva amada por los riosuceños y muy atrayente para los visitantes. Compleja, porque consolida y representa física y simbólicamente las cosmovisiones de tres etnias: la indígena, la afro-descendiente y la blanca; pero también es quien da origen al carnaval: dos pueblos unidos y 'sentenciados' por un diablo a la alegría, quien se pronuncia cuando la rivalidad y las injusticias abundan, pero que permite y celebra de la mano con el pueblo cuando la armonía rige (Morales, 1989). Particular, porque a pesar de ser un pueblo altamente creyente, rompe con todos los esquemas de la concepción judeocristiana del diablo. Sin embargo, en algún momento de la historia y considerando las muchas versiones de la fundación de Riosucio, el diablo unificó a los pueblos a través de la fiesta, pero también amenazó con castigos si la paz no perduraba. Por supuesto, esta imagen se ha ido transformando, pero las similitudes con la imagen de un diablo poderoso son evidentes, en la medida en que el de Riosucio tiene una gran consciencia política y festiva que aprueba o desaprueba el estilo de vida de un pueblo y una sociedad, y de quienes dan vida a su figura y al carnaval. "Su majestad" ya no seduce al hombre para hacerlo 'pecar' en contra de un ser supremo y de sí mismo, sino, para invitarlo a festejar, criticar y seguir dándole vida a la tradición festiva consolidada en el pueblo hace más de cuatrocientos años. Pese a lo anterior el diablo no es el personaje principal del carnaval (Bueno, 2012), por el contrario, es sólo uno de los elementos que le dan vida de la mano con el himno, la bandera, los matachines, las cuadrillas y la literatura matachinesca. Y Festiva, porque se consolida en la emoción de un pueblo que vive en razón de su fiesta, una de las más extensas del mundo: inicia seis meses antes con rituales mensuales preparatorios y culmina en seis desenfrenados días de carnaval durante el mes de enero.

\section{Formas organizativas y festivas del diablo riosuceño:}

Se puede considerar al diablo como un ente que configura una serie de actores y dinámicas desde dos perspectivas: la organizativa y la festiva. La primera se puede entender desde una dimensión logística que tiene en cuenta las implicaciones del montaje y aparición del diablo. Mientras que la segunda está relacionada con el momento en sí, con la práctica y las lógicas en juego durante dicha aparición. Sin embargo, estas dos terminan convertidas en una sola, pues en la medida en que se ejecuta una, la otra también opera, son momentos paralelos en la fiesta. En ese sentido, se pueden distinguir tres principales formas organizativas/festivas en el Carnaval de Riosucio: 
1. La variedad de actos en los cuales la figura del diablo aparece como eje. Estos actos están integrados por desfiles y ceremonias en donde "su majestad" es el protagonista. La entrada del diablo, el desfile de diablos o noche roja, la lectura del testamento y el entierro del calabazo centran su atención en Satán. En ellos, los relatos y actos artísticos preparados están dirigidas a él, o bien, es él quien los lleva a cabo. Por lo regular son desfiles y eventos que aglutinan a muchas personas a su alrededor, quienes celebran con música, cantos y bebida. Los actos pueden ser solemnes o jocosos, depende del momento del carnaval en que se ejecuten. Por lo regular, los que se hacen al inicio desbordan alegría, incluso los dirigentes le advierten al público que debe evitar ciertos comportamientos. Por el contrario, si se lleva a cabo al final, la nostalgia invade al pueblo y el acto adquiere matices de ritual solemne. Los elementos clave a destacar en estas manifestaciones, tienen que ver con el nivel de organización de los actos, cada uno, de manera impecable, maneja un concepto, disfraces, guión, logística y matachines que permiten que el público disfrute de ellas.

2. Los actores o grupos organizados que hacen posible la existencia del diablo son diversos y cumplen un papel determinante. Entre ellos están los diseñadores de la efigie, la Cofradía Satánica, la Junta del Carnaval, las barras y el pueblo carnavalero. Todos coordinan en cierta medida algún momento del Carnaval o dan vida a la aparición y funcionamiento del diablo. Un elemento destacable tiene que ver con el trabajo colectivo que desarrollan para poder cumplir con sus objetivos. Los roles que los sujetos y los colectivos asumen en torno al diablo varían y van desde los que lo materializan, los que lo custodian y los que prefieren alentarlo y adorarlo.

3. Los espacios en los que se mueve el diablo cumplen otro papel importante, pues operan como escenarios que integran las calles por donde desfila, las plazas del pueblo y la Corporación del Carnaval. Estos lugares hacen las veces de mecanismo integrador entre la figura del diablo y el pueblo, en ellos es en donde realmente los habitantes del Riosucio y los visitantes pueden acercarse, apreciarlo e interactuar. Es en la calle donde se construye también gran parte del vínculo del pueblo carnavalero.

\section{Diablos del Carnaval de Riosucio 2013}

Oh Diablo del Carnaval, despierta y vuelve a la vida, y con tu cola encendida, ven mi mente a iluminar, para poder continuar, $y$ salir bien de este apuro, de este trance negro y duro, en que voy a penetrar ${ }^{3}$. (Junta del Carnaval de Riosucio 2012, p.2)

El pueblo ha esperado ansioso la llegada del carnaval, el cual empieza a prepararse desde el mes de julio de 2012. Entre voceos, disfraces, decretos y festejos, se enuncian versos que evocan su llegada. Durante los seis meses de preparación para el carnaval, se empieza a sentir el anhelo de la llegada de la fiesta, los amigos, el guarapo y, por 
supuesto, el diablo. Paulatinamente, su figura va instalándose en la estética del pueblo, anunciando que la fiesta, con el paso de cada mes, está más cerca. Es así como en los almacenes más concurridos del municipio empiezan a comercializarse camisetas, collares, antifaces y cachos que incentivan a locales y visitantes a participar del Carnaval.

En enero la ansiedad desbordada se materializa en la ambiente general del pueblo que espera con toda la alegría y hospitalidad al diablo. Las calles y casas, los disfraces, los perros, los niños, la comida, las artesanías, todo gira en torno a una estética 'roja y cornuda' que semeja la apariencia del diablo fuerte (un diablo que emerge de las montañas del Ingrumá), alegre (que invita a la fiesta), bonachón (que reconcilia) y exigente (un diablo político). El carnaval inicia, pero el pueblo y los visitantes esperan ansiosos la segunda noche de festejo, en la cual el diablo desfila por el pueblo y habla por primera vez después de dos largos años. Este acto le permite a Riosucio disfrutar de "su majestad", comentar su satisfacción o no hacia el mismo, admirar su belleza, cantarle y chiflarle. Es el momento en el que estalla la fiesta, que para la versión 2013 tuvo a su supervisor empotrado en la Plaza de la Candelaria ${ }^{4}$ dispuesto a vigilar el carnaval, representado en una efigie de seis metros, sentado entre libros, una serpiente y un calabazo.

La estética del carnaval constituye uno de los tantos componentes que lo hace envolvente. La capacidad del diablo para contagiar y vestir a un pueblo de carnaval, de explorar sus diversas formas de presentación y representación reflejadas en cachos, capas, alas y disfraces de todos los colores y formas posibles, de dar paso a procesos de creación en un trabajo, la mayoría de veces artesanal y prolijo, digno de admiración. El carnaval y el diablo se reinventan cada dos años y a su vez renuevan la estética de un pueblo capaz de revivir su tradición y materializarla en las diversas formas y dinámicas que la fiesta posibilita. La figura del diablo junto a la curiosidad y creatividad de sus seguidores permean las posibles y diversas formas organizativas y festivas del carnaval, sus disfraces, la literatura, y el sinfín de elementos que componen la fiesta y su estética en todo su esplendor, dándole vida y fuerza al carnaval de Riosucio y a su ícono: el diablo.

En esa medida, el diablo oficial ${ }^{5}$ se configura como una forma organizativa que en su devenir configura una gran cantidad de actores y actividades: la convocatoria de diseño, el jurado que lo elige, el o los diseñadores que materializan el concepto, La Cofradía Satánica que lo custodia desde su primera aparición en días de carnaval, las Caravanas que desfilan a su lado, el pueblo que lo aclama y sigue, que lo aprueba o desaprueba, las personas que realizan el guión de los textos con los cuales "su majestad" se presenta ante el pueblo", la persona que realiza la voz en off y el sujeto que lo encarna en el último día. 
La versión 2013 del carnaval contó con la particularidad de tener tres diablos. Esta situación permite enfatizar que el diablo como figura icónica genera un lugar de disputa, pues además de ser un símbolo, es una forma de discusión política entre los hacedores del Carnaval y el pueblo: ¿qué debe ser y qué no debe ser el diablo en Riosucio?

El diablo oficial, "su majestad": la Corporación del Carnaval estableció una convocatoria en la que enunció las características para la elaboración del diablo del Carnaval de Riosucio 2013. El aspecto de este debía considerar rasgos como el color, la figura humana, elementos animales como los cuernos, cola, alas, colmillos, garras; rasgos 'masculinos' y gestos que enunciaran poder, picardía, alegría y bondad. Además, debía contar con un atuendo que resaltara la fuerza de su corporalidad, y portar elementos como el tridente, la serpiente y el calabazo, claves en la tradición artística. Tenía que incorporar también mecanismos de movilidad e iluminación que estuvieran acordes con sus dimensiones y las de la carroza. Por último, el artista debía hacer una réplica pequeña del Diablo para su quema al final del carnaval.

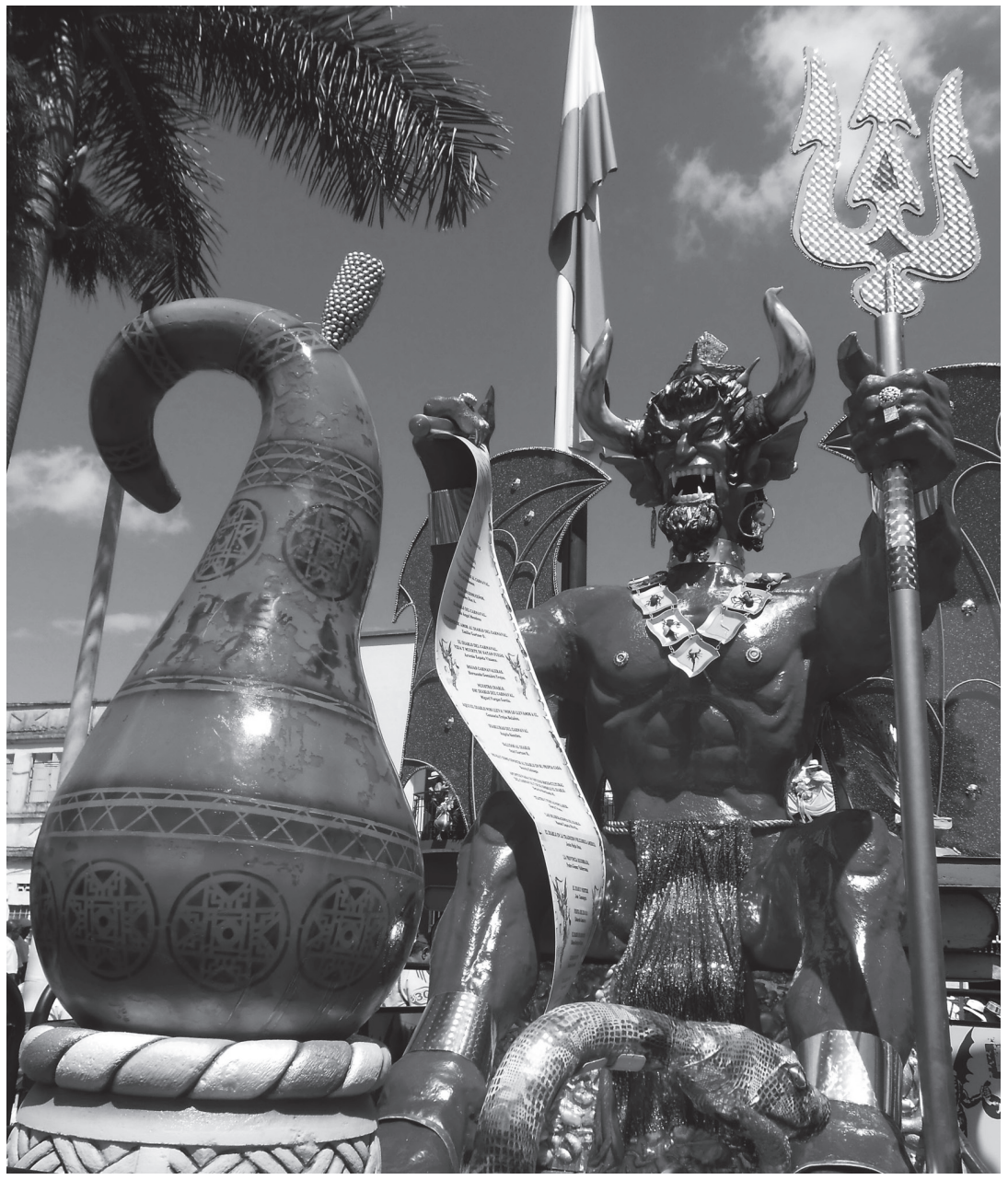

Figura 1. Diablo Oficial del Carnaval de Riosucio 2013. Fotografía: Nathalia Cárdenas 
Esta versión del diablo fue elaborada por el reconocido maestro Gonzalo Díaz, en compañía de su hijo. El concepto trabajado rindió homenaje a los 100 años de historia del himno del carnaval y a la importancia de la literatura matachinezca dentro del mismo. Contó con los acostumbrados elementos que lo han acompañado a lo largo de la historia como símbolo del sincretismo cultural: la serpiente y el calabazo. Además, incorporó a su esbelta figura finísimos acabados que complementaban su porte: la minuciosidad de los dibujos del calabazo y los libros, los colores y materiales de la serpiente; el traje y el canasto que portaba en la cabeza; y los elementos faciales tales como las pestañas y los dientes.

Este diablo es el más esperado, muchos en el pueblo incluso manifiestan que el carnaval no inicia hasta que no desfila. En la segunda noche de carnaval el pueblo en pleno lo esperan. Este acto se convierte en todo un ritual: el diablo empotrado en una carroza y con un manto que cubre su cara, es observado y aclamando por la mayoría y custodiado por un grupo de personas compuesto por diferentes barras y matachines que se encargan de animarlo, y por un equipo especial de escoltas llamado la Cofradía Satánica, que lo acompaña hasta su posesión en la plaza.

Una vez empotrado en una esquina de la Plaza de La Candelaria, congrega a sus admiradores a detallarlo, conversar sobre su apariencia, discutir sobre si es o no lo esperado y, por supuesto, a tomarse fotos. En 2013, al parecer, el diablo había cumplido con las expectativas de locales y visitantes, sus rasgos fuertemente 'masculinizados', el movimiento de su boca y cabeza, los colores y el concepto se ajustaron perfectamente al público expectante.

La diabla no oficial: a pesar de generar disputas entre los organizadores del carnaval y sus creadores, esta es ya un personaje reconocido y esperado cada dos años. Históricamente la diabla ha sido realizada por quienes se autodenominan La Barra de los 30, dirigidos e incentivados por Beto Guerrero, el sujeto que decidió materializar la idea de la figura femenina de satán y la cuota de transgresión a la tradición desde el ejercicio creativo y colaborativo de artistas callejeros, jóvenes mochileros visitantes y bohemios del pueblo. La diabla se fabrica con un bajo presupuesto y gracias a las donaciones de materiales y trabajo voluntario de amigos del grupo en un taller callejero improvisado, cerca de la galería del pueblo y justo frente a la casa de Beto. Un lugar adornado con afiches y murales de todo tipo de diablas y diablos, incluyendo alusiones al equipo de fútbol América de Cali. La construcción de la efigie es artesanal, empieza solo unos meses antes de enero, se hace a contrarreloj y su aparición se concreta el día sábado, casi siempre, antes de que lo haga el diablo oficial. 
La diabla siempre es ubicada en la Plaza de La Candelaria, justo antes de la iglesia, y mirando de frente el tablado que se instala durante la época de carnaval. Es custodiada por miembros del grupo, pues a pesar de que ya es mejor recibida en comparación con años anteriores, hay quienes todavía atentan contra ella, rasgándole su piel o intentando quemarla, incluso en ocasiones la policía ha pretendido retirarla. Para la versión 2013, el diseño fue creado por Beto: una diabla desnuda con sus ya conocidos y grandes senos al descubierto, con piel de color naranja encendido, alas negras y botas blancas. Empuñaba un bastón con un cráneo animal y señalaba imponente hacia su derecha. Midió aproximadamente tres metros y estaba construida con materiales como periódico, costales, bolsas para basura, espuma y cabuya, dispuestos sobre una estructura de hierro que se reutiliza cada dos años. Para esta ocasión, la diabla compartió plaza junto a "su majestad" y murió también minutos después de que éste lo hiciera.

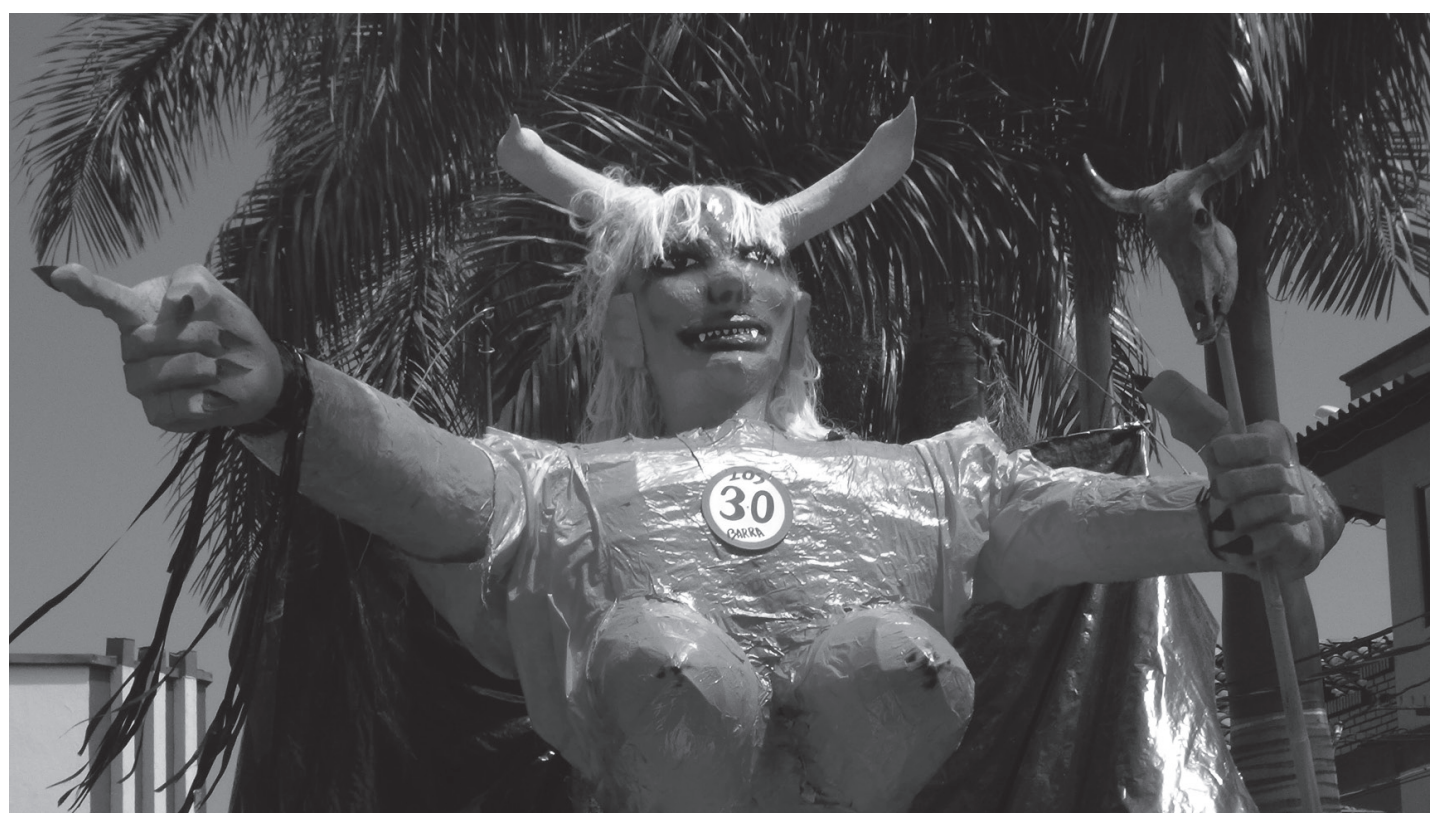

Figura 2. Diabla no oficial del Carnaval de Riosucio 2013. Fotografía: Nathalia Cárdenas

El diablo no oficial fue autodenominado así por su creador Gustavo Cardona, un riosuceño con formación profesional como publicista, quien para el año 2005 había realizado la efigie del diablo oficial. Para el 2013, y a raíz de una serie de tensiones surgidas entre él y la Junta del Carnaval en años pasados, y de diferencias con relación a los términos de convocatoria tradicionales para el diseño del diablo, decidió sacar adelante su propuesta de diablo. Esta fue impulsada y realizada por él y unos cuantos familiares y amigos, que, entre cuotas, donaciones de conocidos y repartición del trabajo salió adelante en solo once días. 


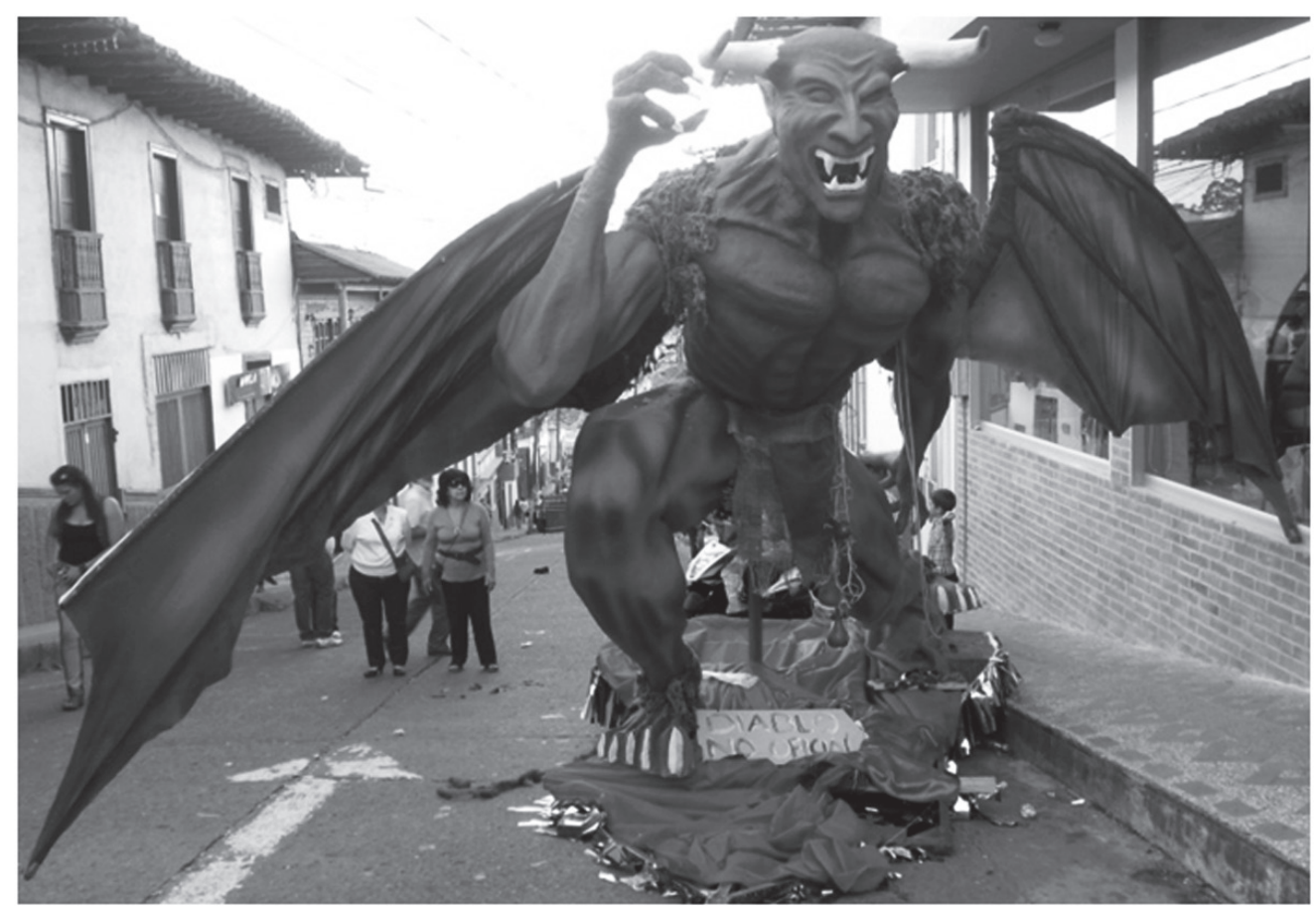

Figura 3. Diablo no oficial del Carnaval de Riosucio 2013. Fotografía: Aurora.

Como resultado se presentó una renovada figura del diablo, que materializaba la fuerza, dinámica, energía y movilidad que caracteriza al carnaval. Este diablo, un poco más elaborado que la diabla, pero no lo suficiente como el oficial, incorporó también un mecanismo de iluminación para sus ojos y un efecto que expedía humo de su boca.

Fue ubicado en la esquina de la cafetería La Vienesa, de propiedad de la familia de Gustavo. Así, esta efigie, que según su creador solo aspiraba a cumplir la labor de recordarle a la gente las posibles formas de encarnar la figura del diablo, provocó curiosidad entre riosuceños y visitantes que se acercaban para tomarse fotos, criticarlo y admirarlo; señal quizá positiva y transgresora de la emergencia de nuevos elementos en el carnaval.

\section{Consideraciones finales: el papel pedagógico de la construcción social del diablo.}

El diablo ha sido considerado a lo largo de la historia como un mito y en Riosucio no es la excepción (Vignolo, 2008). Sin embargo, la mitología de este pueblo, más que concentrarse en la figura del diablo, lo hace en el carnaval como tal. Éste como elemento integrador, constituye un complejo y festivo mito que explica y recuerda el origen de un pueblo, celebra la convergencia de las etnias en los procesos políticos y culturales vividos, y además, tiene la posibilidad de reinventarse cada dos años y generar nuevas formas de representación, encuentro, creación y diversión. 
En esa medida, el diablo enmarcado dentro de un mito se configura como una figura retórica y un elemento semiótico, el cual se vale de las posibilidades de la literatura matachinezca y las características estéticas para presentarse y proclamarse cómo el ícono de un carnaval. Este es un diablo con postura política, con mirada audaz y pícara, que piensa en el bienestar del pueblo desde perspectivas sociales y culturales. Se vale de la palabra para aprobar o desaprobar, comunicar su satisfacción o no respecto a las decisiones de los dirigentes, al comportamiento del pueblo y de los visitantes, a su propia imagen. El diablo es un personaje matachinezco en la medida en que promueve lo festivo, unifica y alegra, pero a la vez es propositivo: permite y se recrea.

En ese sentido, si enunciamos que el diablo es fiesta, obra y producción simbólica de un mito que rige a un pueblo como Riosucio, damos paso a la reflexión sobre su papel dentro del carnaval, pensado como un importante espacio pedagógico. Así, la dimensión pedagógica del carnaval, impulsada desde una figura como la del diablo, se puede abordar desde de dos perspectivas:

La primera, posibilita dimensionar lo puesto en juego en la construcción de la figura del diablo, dando paso a la compresión del proceso que implica entender el carácter pedagógico de las diversas formas organizativas y festivas que giran en torno al mismo. Organizarse para sacar adelante un proyecto colectivo implica poner en común subjetividades, las cuales a su vez, empiezan a asumir roles dentro de la tarea colectiva. Así, la variedad de tareas que oscilan y van desde escribir el discurso que el diablo va a enunciar, hasta organizar las calles por las cuales este desfila, implica una relación constante entre lo que se enseña, lo que se aprende y lo que implica hacerlas. La investigación literaria que se hace para el discurso del diablo, el género, el tono, la forma, la construcción de un concepto acorde con el momento sociohistórico cultural del pueblo, implica una tarea intelectual alta. Consolidar el concepto de su diseño, articular los elementos tradicionales y negociar con los emergentes. Planear los recorridos por las calles, las estaciones. Disponer grupos para su custodia y animación. Que el pueblo aprenda a disfrutar del desfile, comprenda en qué momentos puede intervenir y en cuáles no, conserve los límites entre la bebida y respeto por el acto y la señalización, etc. Todas son una gran tarea colectiva de aprendizaje, que se desarrolla en un proceso de ensayo y error.

La segunda, implica atender a la dimensión estética del diablo como un componente educativo. Bajo esa lógica, la estética como la concepción sobre lo bello, está determinada por el lenguaje, el cual posibilita su entendimiento a través de los sentidos. Asociar elementos, características y asignarles categorías de bello, feo, grotesco, bueno, etc, es más una caracterización que está ligada a las emociones y sensaciones que estos producen en la experiencia de los sujetos, las cuales se convierten en juicios de valor. Lo estético también implica movilizar a nivel subjetivo capacidades para reflexionar e imaginar, para determinar juicios 
y opiniones sobre su entorno y los elementos que lo componen. En esa medida, los productos estéticos no solo responden a lógicas artísticas, sino que cobran sentido y significado en contextos y procesos sociohistórico culturales, cumpliendo funciones políticas, psicológicas y sociales; son, en últimas, una interpretación de la realidad (Kant, 1982/2002; Baumgarten, 1975; Platón, 2011). Entonces, ¿cómo se entiende eso de educar estéticamente a un pueblo? Bien, en la medida en que el diablo se constituye como el ícono del carnaval de Riosucio, en torno a él empiezan a configurarse diferentes ejercicios que le dan vida y que permiten comprender su papel. La abstracción de elementos de su figura, como los cachos, cola, cuernos y calabazo empiezan a instalarse en el pueblo durante los días de fiestas, las personas incorporan diferentes objetos a sus disfraces, casas y animales, así pues, estaríamos frente a una "estética diabólica”. Locales y visitantes empiezan a distinguir qué elementos se usan en los desfiles, qué colores, materiales, texturas.

Paralelamente los diseñadores, modistas, artesanos, decreteros, matachines y cuadrilleros en general, aprenden a producir desde diferentes lugares la figura del diablo, no cualquier diablo, uno que cumpla con las características de fuerza, belleza, alegría e inteligencia, lejos de una concepción judeocristiana. Todo el trabajo de negociación que ocasiona el diablo, tiene que ver, como se mencionó inicialmente, con entender el sentido de éste y comprender su historia, su hacer particular en Riosucio. Por ejemplo, enseñar a los niños una historia diferente y negociar con las corrientes religiosas existentes en el pueblo es una tarea educativa importante. Consolidar un ideal de diablo, establecer un orden estético, es una situación que genera disputas, como lo es el caso de la relación entre el diablo oficial y los no oficiales. Así, participar en el carnaval como espectador puede parecer sencillo, pero aprender a conocer sus lógicas estéticas es un proceso que se pule cada vez más con cada participación en él, con la exploración del significado de sus colores y el disfrute de su alegría.

Finalmente, entender el diablo y las dinámicas del carnaval como manifestaciones festivas populares y prácticas sociales que constituyen el hacer de un pueblo a través de la interrelación de historias de vida, en donde a su vez, la concepción misma de una figura simbólica del diablo crea roles, trayectorias, jerarquías y compromisos con la fiesta, desde una apuesta que fortalece el tejido social de un pueblo y de quienes se unen a su celebración, es, en definitiva, una tarea de aprender a relacionarse con otros, organizarse, convivir en el 'caos', sacar adelante una fiesta y depositar todo el entusiasmo en proyectos festivos y estéticos colectivos. 


\section{Notas}

${ }^{1}$ Este proyecto fue financiado con recursos de la Convocatoria Interna de Investigación 2012-1 de la Universidad del Valle.

${ }^{2}$ El proyecto estuvo a cargo del profesor Armando Henao Velarde, como investigador principal. Diana Sánchez -Estudiante de la Maestría en Educación Popular- y Juan Gabriel Arcila-Estudiante de la Maestría en Psicología Social- participaron como asistentes de investigación. Y Nathalia Cárdena y Arley González, estudiantes del Programa Académico de Recreación se vincularon como monitores de investigación. La investigación se ocupó del estudio de lo festivo desde dos dimensiones de la Recreación: la primera, como actividad social general y la segunda, como proceso educativo. Para ello se seleccionó el Carnaval de Riosucio como objeto empírico de manera que permitiera comprender la dimensión educativa del carnaval mediante el estudio de sus formas recreativas y organizativas.

${ }^{3}$ Versos extraídos de los textos de los voceos para la fase preparatoria de la versión 2013 del carnaval.

${ }^{4} \mathrm{Si}$ bien la historia y el carnaval giran en torno a las dos plazas, las cuales se dividen las actividades a realizar. Desde hace muchos años la efigie del diablo es empotrada en la Plaza de San Sebastián y sólo en contadas ocasiones había tenido lugar en La Candelaria. Para la versión 2013 del Carnaval de Riosucio, la efigie fue empotrada en la esquina de la Plaza La Candelaria, dirigiendo su mirada hacia la Plaza de San Sebastián, justo al finalizar la Calle del Comercio.

${ }^{5}$ El diablo oficial es la efigie patrocinada económicamente y aprobada por la Corporación del Carnaval. En el Carnaval existen otras efigies que se referencian más adelante en este documento.

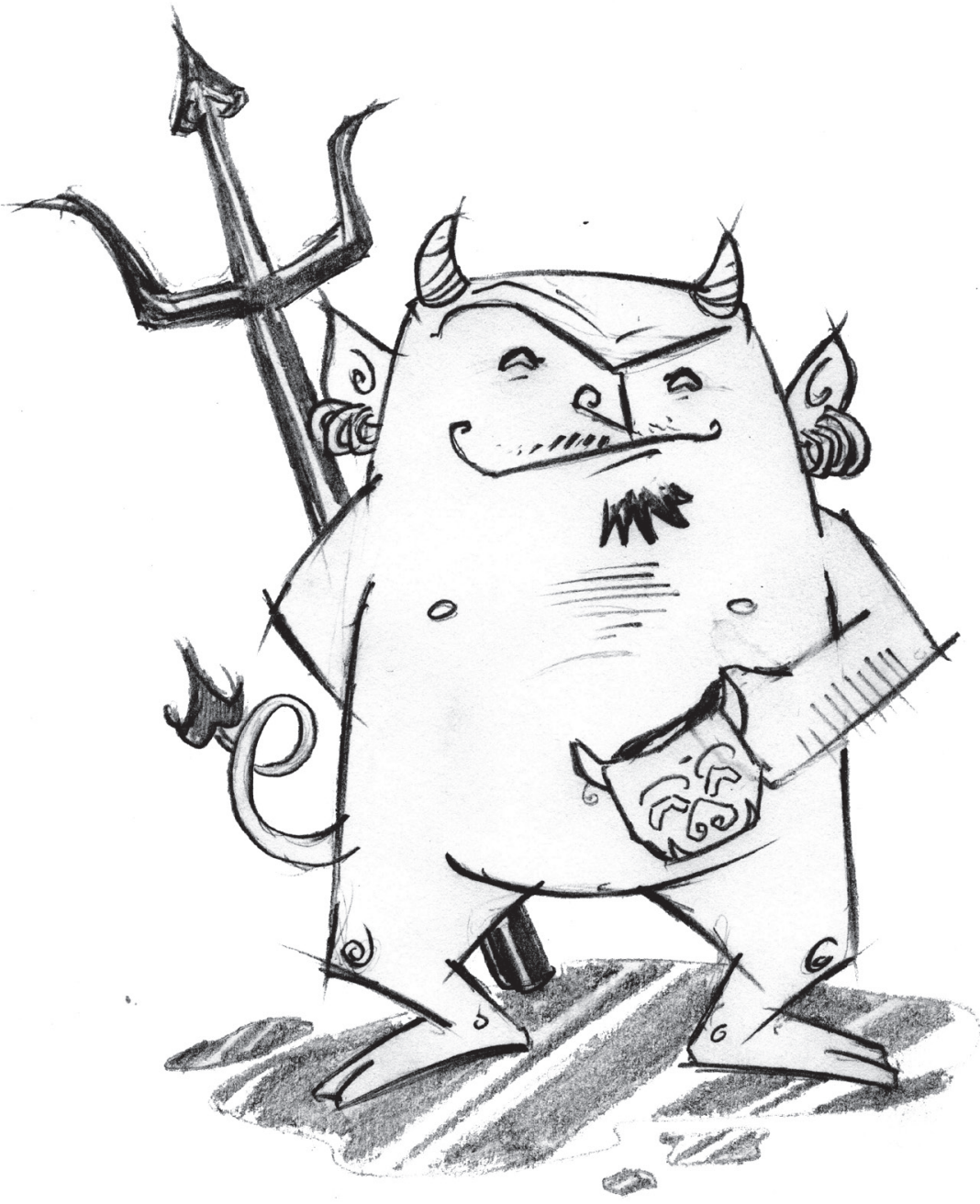




\section{Referencias}

Arboleda Mora, C. (2011). El estudio del diablo. Parte de: Fiestas y Nación en América Latina: Las complejidades en algunos ceremoniales de Brasil, Bolivia, Colombia, México y Venezuela. Bogotá, Colombia: Intercultura.

Barthes, R. (1964). Semántica del objeto. El arte y la cultura, (pág. 6). Venecia.

Baumgarten, A. G. (1975). Reflexiones filosoficas acerca de la poesia. Argentina : Editorial Aguilar .

Bueno Rodríguez, J. (2012). El Carnaval de Riosucio: Estructura y Raíces. Tomo I. Manizales, Colombia: Editorial Manigraf.

Diablos de las Américas. (s.f.). -http://www.diablosfestivos.org/. Consultada el 10 de 03 de 2013

Henao, A. (2012). Notas de trabajo.

Idoyaga Molina, A., \& TORRES, S. (2007). El carnaval, el diablo y la calificación del tiempo. Análisis de un mito etiológico del noroeste Argentino. Mitológicas, vol. XXII, 93-103.

Kant, I. (1982). Lo bello y lo sublime. España: Espasa-Calpe.

(2002). Crítica de la razón pura. En I. KANT, Primera parte de la Doctrina elemental transcendental: La estética transcendental (págs. 29-43). España: Alianza Editorial.

Morales, O. (1989). Facetas míticas del Diablo del Carnaval de Riosucio. Bogotá, Colombia: Ed. Carrera. Paz, O. (1993). Lévi-Strauss o el nuevo festín de Esopo. Barcelona: Seix Barral.

Platón. (2011). Diálogos (v1). En Hipias Mayor. España: Gredos.

Carnaval de Riosucio. (s.f.). Web oficial: http://www.carnavalriosucio.org/. Consultada el 10 de 03 de 2013

Soto, J. E. (2012). El diablo en la Cultura Popular del Caribe Colombiano. Del Corpus Christi al Carnaval de Barranquilla. Colombia: La Iguana Ciega.

Torres, M. (2002). Diablos y Carnavales en América. Tomado de: http:/ / documentacion.cidap.gob. ec:8080/handle/cidap/370

Vignolo, P. (2008). Carnaval, ciudadanía y mestizaje en Colombia. Las metamorfosis delcarnaval: apuntes para la historia de un imaginario. Bogotá: Universidad Nacional de Colombia.

Recibido: 30 de abril / Aprobado: junio 1 de 2015 